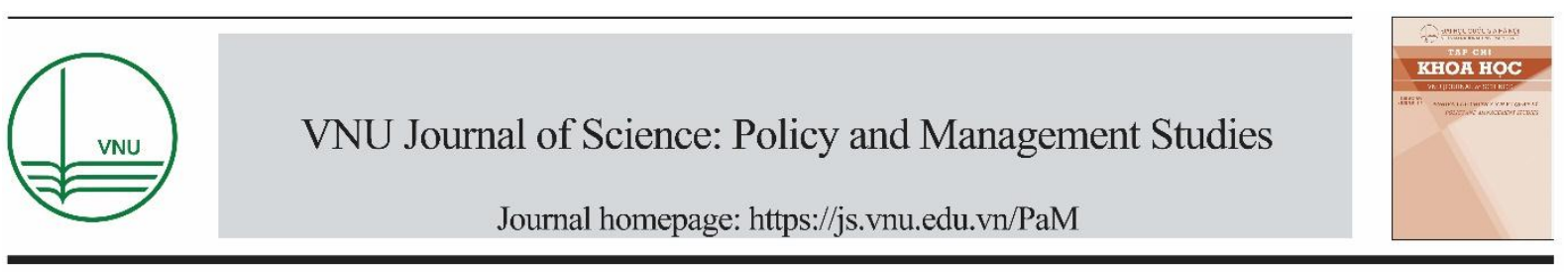

Review Article

\title{
National Human Resources Development Strategy in the World and Lessons for Vietnam
}

\author{
Pham Xuan Truong*, Tu Thuy Anh \\ Faculty of International Economics, Foreign Trade University, \\ 91 Chua Lang, Dong Da, Hanoi, Vietnam \\ Received 14 August 2019 \\ Revised 21 September 2019; Accepted 24 September 2019
}

\begin{abstract}
Human resource is always a vital driving force for socio-economic development of any country in the world. Developing human resource is therefore a top priority mission in development policies at every level, from the firm scale to the national scale. In order to unify human resource development activities, an appropriate strategy is needed for direcing them. After all, human resource will be utilized by firms, hence strategy for human resource development (HRD) must be built and developed at the firm level first. As a result, strategy for HRD at the firm level is studied and intensively applied both in theory and practice. At the national level, the concept of national human resource development (NHRD) is still ambiguous and strongly debated among scholars partially because there are a number of countries, though without a clear NHRD plan, having competent human resources. There are also a lot of countries having succeeded in implementing their own NHRD strategies. The article examines these strategies to draw relevant lessons for Vietnam in its search for a NHRD efficient strategy.
\end{abstract}

Keywords: Strategy, human resource development, human resource development strategy, strategy for national human resource development.

\footnotetext{
* Corresponding author.

E-mail address: truongpx@ftu.edu.vn
}

https://doi.org/10.25073/2588-1116/vnupam.4194 


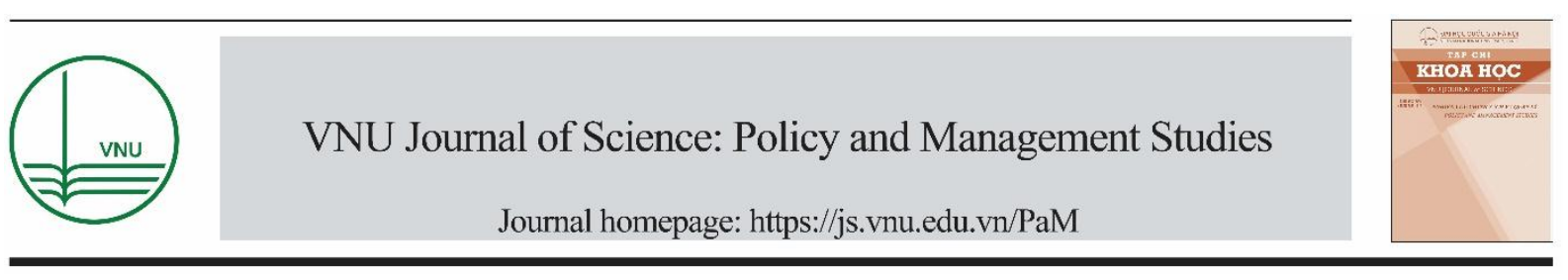

\title{
Chiến lược phát triển nguồn nhân lực quốc gia trên thế giới và bài học kinh nghiệm cho Việt Nam
}

\author{
Phạm Xuân Trường, Từ Thúy Anh \\ Khoa Kinh tế Quốc tế, Truờng Đại học Ngoại Thuơng, 91 Chùa Láng, \\ Đống Đa, Hà Nội, Việt Nam \\ Nhận ngày 14 tháng 8 năm 2019 \\ Chỉnh sửa ngày 21 tháng 9 năm 2019; Chấp nhận đăng ngày 24 tháng 9 năm 2019
}

\begin{abstract}
Tóm tắt: Nguồn nhân lực luôn là yếu tố then chốt trong quá trình phát triển kinh tế - xã hội của bất cứ quốc gia nào trên thế giới. Phát triển nguồn nhân lực vì thế luôn là nhiệm vụ hàng đầu trong các chính sách phát triển từ cấp độ vi mô doanh nghiệp đến cấp độ vĩ mô nền kinh tế. Để các hoạt động phát triển nguồn nhân lực được thực hiện một cách thống nhất thì luôn cần phải có chiến lược phát triển nguồn nhân lực như một kim chỉ nam định hướng cho các hoạt động phát triển nguồn nhân lực cụ thể. Xét cho đến cùng, nguồn nhân lực sẽ được sử dụng trực tiếp bởi các doanh nghiệp để từ đó sản xuất ra của cải vật chất cho xã hội do đó phạm trù chiến lược phát triển nguồn nhân lực được xây dựng và phát triển nhiều ở mức độ vi mô. Lên đến cấp độ vĩ mô toàn nền kinh tế phạm trù chiến lược phát triển nguồn nhân lực thật sự còn tương đối chưa rõ ràng và vẫn được giới học thuật đang nghiên cứu, một phần bởi vì có những quốc gia thực tế không có chiến lược này nhưng chất lượng nguồn nhân lực rất tốt. Tuy nhiên, vẫn có những quốc gia đã đề ra và thực hiện những chiến lược phát triển nguồn nhân lực rất thành công. Bài nghiên cứu sau đây sẽ tìm hiểu những loại hình chiến lược phát triển nguồn nhân lực quốc gia trên thế giới, từ đó rút ra một số bài học kinh nghiệm cho Việt Nam, quốc gia đang trong quá trình hoàn thiện chiến lược phát triển nguồn nhân lực quốc gia của mình.
\end{abstract}

Tù khóa: Chiến lược, phát triển nguồn nhân lực, chiến lược phát triển nguồn nhân lực, chiến lược phát triển nguồn nhân lực quốc gia.

\section{Khái niệm về chiến lược phát triển nguồn nhân lực quốc gia}

"Chiến lược" (có nguồn gốc từ tiếng Hy Lạp là "strategos") là một thuật ngữ xuất phát từ lĩnh vực quân sự thời xa xưa, với ý nghĩa là phương pháp, cách thức điều khiển và chỉ huy các trận đánh. Kenneth Andrews (1971) [1] là người đầu tiên đưa ra các ý tưởng nổi bật này trong cuốn The Concept of Corporate Strategy. Theo ông,

\footnotetext{
*Tác giả liên hệ.

Địa chi email: truongpx@ftu.edu.vn

https://doi.org/10.25073/2588-1116/vnupam.4194
} 
“chiến lược là những gì mà một tổ chức phải làm dựa trên điểm mạnh và yếu của mình trong bối cảnh có những cơ hội và cả những mối đe dọa". Một cách tổng quát nhất có thể hiểu chiến lược là kế hoạch kiểm soát và sử dụng nguồn lực của một tổ chức như con người, tài sản, tài chính...để đạt được những mục tiêu cơ bản trong dài hạn mà tổ chức đề ra.

Về khái niệm phát triển nguồn nhân lực (HRD), tùy từng cách hiểu nguồn nhân lực là gì thì phát triển nguồn nhân lực sẽ mang nội dung tương ứng. Một cách tổng quát nhất có thể khái quát phát triển nguồn nhân lực chính là quá trình tạo lập và sử dụng năng lực toàn diện của con người vì sự hoàn thiện bản thân mỗi con người và sự phát triển của tổ chức nơi con người hoạt động. Xét cho đến cùng nhiệm vụ chuyển hóa nguồn nhân lực như một đầu vào trong quá trình sản xuất thành những thành tựu kinh tế phần lớn thuộc về doanh nghiệp do đây là đối tượng sử dụng trực tiếp nhân lực trong nền kinh tế và cũng là đối tượng nhận được nhiều lợi ích nhất từ việc sử dụng nhân lực. Vì vậy, các lý thuyết cũng như hoạt động thực tế về phát triển nguồn nhân lực được nghiên cứu và triển khai nhiều ở cấp độ vi mô - doanh nghiệp trong đó mọi hoạt động nhằm tạo lập, duy trì và sử dụng có hiệu quả lao động đều hướng tới việc phát triển doanh nghiệp. Ở cấp độ vĩ mô quốc gia, phát triển nguồn nhân lực của một quốc gia (NHRD) chính là sự biến đổi về số lượng và chất lượng nguồn nhân lực trên các mặt thể lực, trí lực, kỹ năng, kiến thức và tinh thần cùng với quá trình tạo ra những biến đổi tiến bộ về cơ cấu nguồn nhân lực [2]. Đây cũng chính là cách tiếp cận của Liên Hợp Quốc (LHQ) đối với khái niệm NHRD khi các cơ quan của LHQ không chỉ tập trung phát triển kỹ năng của người lao động trong các dự án của mình mà còn phát triển cả khả năng học hỏi hay các vấn đề về thể chất (hỗ trợ dinh dưỡng, sức khỏe sinh sản) tâm lý (mức độ căng thẳng, thỏa mãn với công việc) và văn hóa (hòa nhập cộng đồng) [3]. Nói một cách khác các hoạt động NHRD thường có tính liên ngành hơn hoạt động HRD được thực hiện ở doanh nghiệp vì nó liên quan đến các yếu tố phi kinh tế như sức khỏe, tâm lý, văn hóa.
Kết hợp với khái niệm chiến lược nêu ở trên chúng ta có thể xây dựng khái niệm về chiến lược phát triển nguồn nhân lực như sau. Chiến lược phát triển nguồn nhân lực ở cấp vi mô - doanh nghiệp là một hệ thống các chính sách và hoạt động được thiết kế để sử dụng các nguồn lực mà doanh nghiệp đó có cho việc đào tạo, bồi dưỡng nguồn nhân lực trong doanh nghiệp các kỹ năng phẩm chất cần thiết để họ giúp doanh nghiệp hoàn thành các mục tiêu trong dài hạn. Trong khi đó chiến lược phát triển nguồn nhân lực cấp quốc gia được hiểu là một hệ thống các chính sách và hoạt động được thiết kế dựa trên nguồn lực mà quốc gia đó có để đào tạo, bồi dưỡng nguồn nhân lực trong một quốc gia các kỹ năng phẩm chất cần thiết để họ giúp quốc gia đạt được các mục tiêu kinh tế trong dài hạn. Chiến lược hay các mô hình HRD có thể được thể hiện cụ thể hóa bằng văn bản (viết ra) hoặc không. Tuy nhiên khi thực hiện ở cấp quốc gia thì chiến lược sẽ phải được cụ thể hóa bằng văn bản do chính phủ ban hành. Thông thường chiến lược NHRD bao gồm: mục tiêu trong dài hạn, chỉ số cụ thể hóa cho mục tiêu đó, kế hoạch hành động để đạt được mục tiêu, nguồn lực để thực hiện kế hoạch và cơ quan chịu trách nhiệm thực thi giám sát và đánh giá cuối cùng.

\section{Các chiến lược phát triển nguồn nhân lực quốc gia trên thế giới}

Trước khi nói về các chiến lược (mô hình) NHRD trên thế giới, chúng ta hãy phân tích qua một số các yếu tố quyết định các quốc gia sẽ theo chiến lược (mô hình) nào. Gold và cộng sự (2013) [4] tiếp cận theo phạm vi ảnh hưởng đã liệt kê những nhân tố ảnh hưởng đến sự hình thành và nội dung của $N H R D$ và chia thành hai nhóm: nhóm nhân tố bên trong và nhóm nhân tố bên ngoài. Cụ thể, nhóm nhân tố bên trong bao gồm cấu trúc nền kinh tế, trình độ công nghệ, đặc điểm xã hội (nhân khẩu học, tôn giáo, truyền thống văn hóa), thể chế; nhóm nhân tố bên ngoài bao gồm hoạt động thương mại quốc tế, môi trường an ninh quốc tế, lịch sử quan hệ quốc tế, tỷ giá và dòng vốn đầu tư quốc tế. Các yếu tố bên 
trong thông thường sẽ quyết định số lượng và chất lượng nguồn lực để một quốc gia tiến hành thực hiện chiến lược NHRD, còn các yếu tố bên ngoài kết hợp sẽ quyết định sự phân bổ các nguồn lực này theo hướng nào để phát triển nguồn nhân lực quốc gia. Oh và Choi (2013) [5] tiếp cận theo yếu tố thị trường thì lại nhấn mạnh đến các các điều kiện cung nhân lực (tỷ lệ dân số trong độ tuổi lao động, tỷ lệ lao động qua đào tạo, chất lượng lao động theo thang đánh giá của ILO...), cầu nhân lực (tỷ trọng lao động hoạt động trong khu vực phi chính thức, tỷ trọng lao động làm việc trong các doanh nghiệp vừa và nhỏ, tỷ trọng lao động làm việc trong khu vực R\&D...) và hệ thống hỗ trợ (chính sách của chính phủ, hoạt động của hiệp hội ngành nghề...).

Về phân loại các chiến lược (mô hình) NHRD, Alagaraja và Wang (2012) [6] dựa trên các nghiên cứu thực nghiệm của mình trước đó khi so sánh NHRD được thực hiện ở các quốc gia đã chia chiến lược hay mổ hình NHRD thành 9 nhóm. Đó là: (i) Mô hình được dẫn dắt bởi hệ thống giáo dục (hệ thống giáo dục chính thức, phi chức thức; đào tạo dựa theo yêu cầu công việc từ các doanh nghiệp; hệ thống trường cao đẳng); (ii) Mô hình xét tới tác động của thị trường lao động, việc làm tới hệ thống đào tạo nghề, phát triển kỹ năng và huấn luyện tại nơi làm việc; (iii) Mô hình trường dạy nghề, thể chế học việc và hệ thống đào tạo được dẫn dắt bởi các ngành công nghiệp xét tới tác động của văn hóa và lịch sứ; (iv) Mô hình chính phủ dẫn dắt trong đào tạo, dạy nghề tại cấp vùng và địa phương; (v) Mô hình xét tới mối quan hệ giữa thị trường lao động, đặc điểm của thể chế và nhu cầu từ các doanh nghiệp; (vi) Mô hình hệ thống quốc gia về kỹ năng lao động được hình thành bởi các nhân tố phụ thuộc lẫn nhau là Nhà nước, thị trường vốn, thị trường lao động; (vii) Mô hình chính sách và thực thi HRD trong một kế hoạch phát triển kinh tế tổng thể cấp quốc gia; (viii) Mô hình NHRD có xét tới yếu tố chính trị, văn hóa, xã hội, kinh tế hiện tại; (ix) Mô hình nhấn mạnh vai trò của chính phủ trong mọi hoạt động của NHRD.
Mclean G.N (2012) [7] dựa trên vai trò của chính phủ, thị trường lao động và các thể chế hỗ trợ đã rút gọn các chiến lược NHRD thành 5 nhóm: (i) chiến lược phát triển nguồn nhân lực quốc gia theo hướng tập trung hóa (centralized NHRD strategy); (ii) chiến lược phát triển nguồn nhân lực quốc gia trong trạng thái kinh tế chuyển đổi (transitional NHRD strategy); (iii) chiến lược phát triển nguồn nhân lực quốc gia do Nhà nước kiến tạo (neo-market with government initiated partnership based NHRD strategy) iv) chiến lược phát triển nguồn nhân lực quốc gia theo hướng thị trường tự do (free market based NHRD strategy) và v) chiến lược phát triển nguồn nhân lực quốc gia dành cho nước nhỏ (small nation's NHRD strategy). Trong cách chia này, ngoài việc có ít nhóm hơn tạo thuận lợi cho việc nghiên cứu thì việc phân loại chiến lược NHRD cũng được trở nên thống nhất khi lấy vai trò tương đối giữa nhà nước và tư nhân làm căn cứ chung. Ở chiến lược v) xét cho đến cùng khi các quốc gia nhỏ không thể một mình thực hiện được chiến lược NHRD của mình mà phải liên kết với các quốc gia khác tương đồng với mình (thường thấy ở nhóm các quốc gia là quốc đảo) để cùng thực hiện một chiến lược phát triển nguồn nhân lực ở phạm vi khu vực thì cũng phải đứng trước sự lựa chọn lấy vai trò của nhà nước làm chủ đạo (chiến lược NHRD tập trung hóa) hay lấy vai trò của tư nhân làm chủ đạo (chiến lược NHRD theo hướng thị trường tự do) hay nhà nước kết hợp với tư nhân (chiến lược NHRD trong trạng thái kinh tế chuyển đổi, chiến lược NHRD do Nhà nước kiến tạo).

Kết hợp với các yếu tố tác động đến việc lựa chọn chiến lược NHRD, chúng ta có thể nhận thấy ứng với ba mô hình vận hành nền kinh tế trên thế giới (kế hoạch hóa tập trung - nhấn mạnh vai trò chủ đạo của nhà nước, thị trường tự do - nhấn mạnh vai trò chủ đạo của thị trường và hỗn hợp - kết hợp vai trò của thị trường và nhà nước), các chiến lược NHRD về mặt tổng quát cũng có thể được chia thành 3 nhóm. Nhóm 1 là nhóm chiến lược NHRD phần lớn do chính phủ quyết định, đây là chiến lược NHRD tập trung hóa, theo cách tiếp cận thị trường nhóm quốc gia phù hợp để thực hiện chiến lược này là các quốc gia đang phát triển có nguồn cung nhân 
lực dồi dào nhưng chất lượng chưa cao; cầu về nhân lực còn hạn chế trong đó khu vực công chiếm ưu thế; hệ thống hỗ trợ bao gồm chính sách chính phủ và các tổ chức dân sự liên quan đến lao động chưa hiệu quả; tuy nhiên cũng có những ngoại lệ nếu như vai trò của chính phủ là rất lớn trong việc thúc đẩy nền kinh tế trong quá khứ thì chiến lược NHRD ở thời kỳ sau cho dù lúc này quốc gia đã là một nước phát triển vẫn gần như do chính phủ kiểm soát. Nhóm 2 là nhóm chiến lược NHRD có sự phối hợp giữa nhà nước và thị trường bao gồm chiến lược NHRD trong trạng thái kinh tế chuyển đổi (giảm bớt vai trò của nhà nước và bắt đẩu đề cao vai trò của khu vực tư nhân) và chiến lược NHRD do nhà nước kiến tạo (vai trò của nhà nước chỉ ở mức định hướng còn khu vực tư nhân là khu vực chính thực hiện chiến lược). Theo cách tiếp cận thị trường, nhóm quốc gia phù hợp để thực hiện chiến lược này là các quốc gia chuyển đổi đang trong giai đoạn chuyển từ nước đang phát triển sang nước phát triển với nguồn cung nhân lực dồi dào nhưng ở trình độ trung bình, nguồn cầu nhân lực vừa phải khi các doanh nghiệp trong nước bắt đầu phát triển cùng với khu vực FDI bắt đầu khởi sắc; hệ thống hỗ trợ bao gồm chính sách của chính phủ và các tổ chức liên quan đến lao động không chỉ hoàn thiện hơn do sự phát triển của nền kinh tế mà còn bởi các quốc gia này thường có mức độ hội nhập cao và vì thế sự cải thiện còn đến từ việc cập nhật và thích ứng với các tiêu chuẩn quốc tế về lao động. Cuối cùng nhóm 3 là nhóm chiến lược NHRD theo hướng thị trường tự do, đây là chiến lược NHRD mà thực chất không có bất cứ điều hành gì về chiến lược, kế hoạch phát triển nguồn nhân lực của chính phủ, các chiến lược này thông thường được đưa ra bởi các hiệp hội ngành nghề, công ty, tập đoàn lớn cũng như các công đoàn lao động. Theo cách tiếp cận thị trường, chỉ có những quốc gia phát triển (thậm chí là rất phát triển) mới thực hiện chiến lược này bởi cung lao động, cầu lao động ở những nước này có trình độ cao, được tổ chức và vận hành đồng bộ, đủ khả năng để đưa ra phương hướng và các hoạt động cụ thể hiệu quả để phát triển nguồn nhân lực ở cấp độ vi mô từ đó lan tỏa lợi ích đến cả nền kinh tế. Hệ thống hỗ trợ cũng hoạt động rất tốt, chính sách chính phủ chỉ xuất hiện khi thực sự có những vấn đề nghiêm trọng xảy ra.

Nair P.K và các cộng sự (2007) [8] cũng chỉ ra điểm tương tự khi nhận thấy chiến lược NHRD ở các nước đang phát triển thông thường có sự can thiệp lớn của chính phủ còn chiến lược NHRD ở các nước phát triển lại có sự tác động rất rõ ràng từ thị trường, chính phủ chỉ đóng vai trò hỗ trợ . Ngoài ra Nair P.K và các cộng sự (2007) [8] cũng cho rằng chiến lược NHRD ở nước đang phát triển do những hạn chế vốn có về mặt kinh tế, thể chế chỉ tập trung ở mảng giáo dục, còn chiến lược NHRD ở nước phát triển do là những nước có điều kiện hơn nên tập trung vào mảng đào tạo và phát triển toàn diện con người (bao gồm có thể chất, thẩm mỹ...)

Bảng 1. Phân loại các chiến lược NHRD trên thế giới.

\begin{tabular}{|c|c|c|c|}
\hline $\begin{array}{l}\text { Mô hình phát triển } \\
\text { nguồn nhân lực }\end{array}$ & Tính chất & Đặc điểm theo cách tiếp cận thị trường & $\begin{array}{l}\text { Quốc gia tiêu biểu } \\
\text { đang thực hiện chiến } \\
\text { lược }\end{array}$ \\
\hline $\begin{array}{l}\text { Chiến lược tập } \\
\text { trung hóa }\end{array}$ & $\begin{array}{l}\text { Việc lên kế } \\
\text { hoạch NHRD } \\
\text { được thực hiện } \\
\text { bởi chính quyền } \\
\text { trung ương }\end{array}$ & $\begin{array}{l}\text { Nguồn cung nhân lực: dồi dào nhưng chất } \\
\text { lượng thấp } \\
\text { Nguồn cầu nhân lực: phụ thuộc vào khu } \\
\text { vực nhà nước do khu vực tư nhân còn nhỏ } \\
\text { bé } \\
\text { Hệ thống hỗ trợ (thể chế): giáo dục đang } \\
\text { vật lộn ở mức độ phồ thông; đào tạo nghề } \\
\text { và giáo dục đại học còn yếu kém } \\
\text { Thị trường lao động sơ khai, luật lệ liên } \\
\text { quan đến sử dụng lao động còn lỏng lẻo. }\end{array}$ & $\begin{array}{l}\text { Trung Quốc, Các } \\
\text { quốc gia Trung Đông } \\
\text { (trường hợp đặc biệt } \\
\text { Hàn Quốc) }\end{array}$ \\
\hline
\end{tabular}




\begin{tabular}{|c|c|c|c|}
\hline $\begin{array}{l}\text { Chiến lược chuyển } \\
\text { đồi }\end{array}$ & $\begin{array}{l}\text { Việc lên kế } \\
\text { hoạch được thực } \\
\text { hiện bởi ba bên } \\
\text { có sự tham gia } \\
\text { của chính quyền } \\
\text { trung ương, } \\
\text { công đoàn và } \\
\text { doanh nghiệp } \\
\text { (đây là quá trình } \\
\text { di chuyển khỏi } \\
\text { mô hình tập } \\
\text { trung) }\end{array}$ & $\begin{array}{l}\text { Nguồn cung nhân lực: dồi dào nhưng chất } \\
\text { lượng ở mức trung bình } \\
\text { Nguồn cầu nhân lực: vừa phải và tương } \\
\text { đối cân bằng giữa khu vực tư nhân và nhà } \\
\text { nước } \\
\text { Hệ thống hỗ trợ (thể chế): giáo dục phổ } \\
\text { thông đã hoàn thiện } \\
\text { Thị trường lao động bước đầu được hình } \\
\text { thành. Luật lệ liên quan đến sử dụng lao } \\
\text { động đang trong quá trình hoàn thiện }\end{array}$ & $\begin{array}{l}\text { Nam Phi, Thái Lan, } \\
\text { Malaysia, các quốc } \\
\text { gia Nam Mỹ }\end{array}$ \\
\hline $\begin{array}{l}\text { Chiến lược nhà } \\
\text { nước kiến tạo }\end{array}$ & $\begin{array}{l}\text { Các tiêu chuấn } \\
\text { nghề nghiệp } \\
\text { được thiết lập } \\
\text { bởi các doanh } \\
\text { nghiệp và ngành } \\
\text { kinh tế theo } \\
\text { sáng kiến của } \\
\text { chính quyền } \\
\text { trung ương }\end{array}$ & $\begin{array}{l}\text { Nguồn cung nhân lực: dồi dào, chất lượng } \\
\text { cao } \\
\text { Nguồn cầu nhân lực: tương đối lớn và chủ } \\
\text { yểu xuất phát từ khu vực tư nhân } \\
\text { Hệ thống hỗ trợ (thể chế): giáo dục phổ } \\
\text { thông và đại học đã hoàn thiện, đào tạo } \\
\text { nghề cũng trở nên hiệu quả } \\
\text { Thị trường lao động được hình thành đầy } \\
\text { đủ. Luật lệ liên quan đến sử dụng lao động } \\
\text { đã hoàn thiện }\end{array}$ & $\begin{array}{l}\text { Singapore, các nước } \\
\text { Châu Âu (trừ Tây Âu) }\end{array}$ \\
\hline $\begin{array}{l}\text { Chiến lược thị } \\
\text { trường tự do }\end{array}$ & $\begin{array}{l}\text { Không có sự } \\
\text { can thiệp của } \\
\text { chính quyền } \\
\text { trung ương vào } \\
\text { thị trường lao } \\
\text { động, thị trường } \\
\text { lao động được } \\
\text { coi là tự do } \\
\text { tuyệt đối trong } \\
\text { việc thiết lập kế } \\
\text { hoạch quy trình } \\
\text { phát triển nguồn } \\
\text { nhân lực }\end{array}$ & $\begin{array}{l}\text { Nguồn cung nhân lực: vừa phải và chất } \\
\text { lượng cao, một bộ phận lao động có trình } \\
\text { độ rất cao } \\
\text { Nguồn cầu nhân lực: nhiều và gần như } \\
\text { đến từ khu vực tư nhân } \\
\text { Hệ thống hố trợ (thề chế): giáo dục đã làm } \\
\text { tồt cả đền dạy nghề, đại học, sau đại học; } \\
\text { người lao động có khả năng tự học cao } \\
\text { Thị trường lao động đầy đủ, luật lệ liên } \\
\text { quan đến sử dụng lao động chặt chẽ }\end{array}$ & $\begin{array}{l}\text { Mỹ, Tây Âu, Nhật } \\
\text { Bản }\end{array}$ \\
\hline
\end{tabular}

Nguồn: Nhóm tác giả tụ tổng hợp

HỘP 1. CHIẾN LƯợC PHÁT TRIỄN NGUỒN NHÂN LỰC CỦA HÀN QUỐC

Tại Hàn Quốc, chính sách phát triển nguồn nhân lực luôn là một trong những chính sách trọng tâm của chính phủ, điều này được thể hiện vào năm 2003, chính phủ nước này đã đổi tên Bộ giáo dục thành Bộ giáo dục và phát triển nguồn nhân lực. Chính phủ Hàn Quốc coi giáo dục sẽ là nhân tố chính giúp quốc gia này định vị mình là một nước có thu nhập cao trên thế giới.

Kể từ cuối thế kỷ IX, chính phủ Hàn Quốc đã đầu tư rất nhiều để cải thiện hệ thống giáo dục và đưa đến cơ hội học tập cho tất cả các tầng lớp trong xã hội Hàn Quốc kể cả phụ nữ (Bae \& Rowley, 2003) [9]. Theo Tống Mạnh Hùng (2018) [10], trong giai đoạn đầu của công nghiệp hóa, vào những năm 1960 đến những năm 1970 của thế kỷ XX, Hàn Quốc tập trung vào phát triển công nghiệp nhẹ và điện tử, Hàn Quốc đã tập trung hoàn thành phổ cập giáo dục tiểu học, phát triển giáo dục trung học cơ sở, khuyến khích trung học nghề và kỹ thuật, hạn chế chỉ tiêu giáo dục đại học. Sang những 
năm 1980 của thế kỷ XX, khi chuyển từ sản xuất công nghệ trung bình sang công nghệ cao, giáo dục nghề nghiệp và kỹ thuật được coi trọng ngay từ cấp trung học. Hàn Quốc tập trung mở rộng quy mô giáo dục phổ thông, đẩy mạnh đào tạo nghề, nới rộng chỉ tiêu nhập đại học theo hướng phát triển các trường cao đẳng nghề và kỹ thuật, chương trình giáo dục phổ thông, tính thực hành được coi trọng hơn tính hàn lâm. Các trình độ từ dạy nghề đến trung cấp, cao đẳng, đại học, sau đại học được thường xuyên điều chỉnh về quy mô và chất lượng cho phù hợp với đòi hỏi về nguồn nhân lực của tiến tình công nghiệp hóa. Tháng 12/2001, từ những chiến lược về giáo dục một cách bài bản từ những thời kỳ trước, chính phủ Hàn Quốc mới chính thức công bố chiến lược NHRD lần thứ nhất giai đoạn 20012005. Tiếp đó, chiến lược NHRD lần thứ 2 được xây dựng và thực hiện hiệu quả. Nội dung chính của các chiến lược này đề cập tới sự tăng cường hợp tác giữa các doanh nghiệp, các trường đại học và các cơ sở nghiên cứu; nâng cao trình độ sử dụng, quản lý nguồn nhân lực, nâng cao tính chuyên nghiệp của nguồn nhân lực trong khu vực công; xây dựng hệ thống đánh giá, quản lý kiến thức, kỹ năng và công việc, xây dựng kết cấu hạ tầng thông tin cho phát triển nguồn nhân lực, xây dựng và phát triển thị trường tri thức. Chính phủ Hàn Quốc tiến hành rất nhiều các nghiên cứu để xác định NHRD có nên được thực hiện hay không. Do vậy, Hàn Quốc khi xây dựng NHRD đã có luôn một cơ chế giám sát và đánh giá toàn diện [11]. Nhìn chung, chính nhờ chiến lược NHRD được xây dựng một cách tỉ mỉ và khoa học đã giúp Hàn Quốc tạo ra một đội ngũ nhân lực quốc gia có trình độ giúp Hàn Quốc chuyển mình từ một đất nước nghèo đói, lạc hậu thành một trong những nước có nền kinh tế năng động nhất thế giới.

Một trong những điểm nổi bật trong chiến lược giáo dục, đào tạo nằm trong chiến lược NHRD nói chung của Hàn Quốc đó là cách thức đào tạo, lựa chọn và sử dụng nhân tài. Hàn Quốc quan niệm "trẻ em năng khiếu là một bộ phận không thể tách rời tổng thể tài nguyên và trí tuệ được coi là một loại tài nguyên quý nhất của một dân tộc, là tài sản quý nhất trong tương lai", "giáo dục năng khiếu, tài năng là một chiến lược phát triển cơ bản phải được coi là ưu tiên số một so với bất kỳ ngành phát triển nào" [12]. Vì thế, Hàn Quốc đã xây dựng chiến lược cụ thể để phát hiện và tuyển chọn học sinh năng khiếu, từ đó bồi dưỡng đến khi học đại học trở thành nguồn nhân lực chất lượng cao, trình độ cao. Ngoài ra, Hàn Quốc không chỉ quan tâm đến khâu đào tạo mà còn quan tâm đến cả khâu tuyển chọn và thu hút nhân tài. Từ năm 2015, Chính phủ Hàn Quốc giới thiệu hệ thống tuyển dụng mới Tiêu chuẩn Năng lực Quốc gia (National Competency Standards - NCS) nhằm đánh giá trình độ và kỹ năng cho từng công việc của trên 800 ngành nghề trong lĩnh vực công lập. Bộ tiêu chuẩn này đã được Chính phủ Hàn Quốc xây dựng và phát triển từ năm 2002, giúp các công ty tuyển dụng được nhân sự cần thiết không chỉ dựa trên nền tảng giáo dục và bằng cấp mà còn dựa trên năng lực tiềm năng của ứng viên. Đến năm 2015, 130 cơ quan công lập áp dụng bộ tiêu chuẩn này. Dự kiến, đến hết năm 2019, bộ tiêu chuẩn được sử dụng trên khắp các đơn vị, tổ chức thuộc lĩnh vực công. Quá trình tuyển dụng nhân sự ở cả khu vực công lẫn khu vực tư nhân đều được khuyến khích dựa trên thông tin cơ bản của ứng viên và thể hiện của ứng viên trong quá trình tuyển chọn; các thông tin khác về gia thế, trường học, nơi sống sẽ không được tiết lộ. Việc thu hút tuyển chọn nhân tài không chỉ được thực hiện trong khu vực kinh tế tư nhân mà trong cả khối cơ quan nhà nước để đáp ứng khả năng cạnh tranh ở quy mô toàn cầu là mục tiêu mà Chính phủ Hàn Quốc đặt ra.

Chu Văn Cấp và cộng sự (2014) [13] đã tổng kết những đặc mạnh trong chiến lược NHRD của Hàn Quốc như sau. Thứ nhất, chiến lược NHRD của Hàn Quốc coi trọng phát triển giáo dục đặc biệt là giáo dục đại học. Thứ hai, chính sách giáo dục đào tạo nghề được xây dựng phù hợp với đòi hỏi của nền kinh tế. Thứ ba, cải cách giáo dục là nhiệm vụ thường xuyên của Hàn Quốc. Cuối cùng, trong chiến lược luôn có nội dung thu hút nhân tài và đầu tư mạnh cho phát triển khoa học - công nghệ và giáo dục. 


\section{Bài học kinh nghiệm cho Việt Nam}

Theo Báo cáo của Bộ Kế hoạch và đầu tư [14] đến hết năm 2017 thì phần lớn doanh nghiệp Việt Nam vẫn là doanh nghiệp nhỏ và vừa (chiếm 98,1\%), đấy là chưa kể các hộ gia đình kinh doanh trong khu vực không chính thức không được thống kê. Đây cũng chính là đối tượng chính sử dụng nhiều lao động nhất trong nền kinh tế (xấp xỉ 98\% năm 2017). Tuy áp đảo là như vậy nhưng để đối tượng này dẫn dắt nội dung phát triển nguồn nhân lực chắc chắn là điều không hợp lý vì trình độ cũng như tầm nhìn của doanh nghiệp nhỏ và vừa còn hạn chế. Ngược lại với tỷ trọng áp đảo của doanh nghiệp nhỏ và vừa thì các doanh nghiệp lớn trong thời gian gần đây đã có nhiều khởi sắc. Nếu trước đây khoảng mười năm rất khó để chúng ta có thể kể ra một doanh nghiệp tư nhân lớn trong nền kinh tế Việt Nam đặc biệt là trong lĩnh vực sản xuất nhưng hiện nay chúng ta có thể liệt kê một số doanh nghiệp Việt Nam nổi bật như Vingroup, Thaco, HAGL, Viettel cùng những doanh nghiệp FDI rất mạnh như Samsung Việt Nam, Toyota Việt Nam, Intel.... Đây là những đối tượng có những đòi hỏi nhất định về nguồn nhân lực đặc biệt là nguồn nhân lực chất lượng cao, trình độ cao, ngoài ra chính họ cũng đã tiến hành tự đào tạo nhân lực sau khi tuyển dụng một cách bài bản. Do đó đây là một thành phần có thể tham khảo đến khi chính phủ tiến hành xây dựng chiến lược NHRD và các kế hoạch hành động cụ thể sau đó. Bên cạnh đó, với bối cảnh cuộc cách mạng công nghiệp 4.0 đang tác động rất mạnh mẽ vào mọi mặt sản xuất, kinh doanh của doanh nghiệp khiến cho doanh nghiệp thực sự hiểu rõ nhất mình cần nhân lực như thế nào để đủ chất lượng và linh hoạt trong tình hình mới. Vì vậy, một lần nữa đóng góp ý kiến của các doanh nghiệp vào chiến lược phát triển nguồn nhân lực là rất cần thiết.

Việt Nam hiện tại cũng đang ở trong quá trình hội nhập quốc tế sâu rộng. Chúng ta vừa ký kết xong hai hiệp định thương mại thế hệ mới là CPTPP (hiệp định đối tác toàn diện và tiến bộ xuyên Thái Bình Dương) và EVFTA (hiệp định thương mại tự do EU - Việt Nam) trong đó có các tiêu chuẩn mới về lao động trong thương mại. Theo hiệp định CPTPP và EVFTA vừa ký kết thì người lao động được bảo đảm các quyền, lợi ích và các điều kiện lao động cơ bản trong đó có những quyền rất mới ở Việt Nam như quyền được tự do thành lập công đoàn, quyền được đào tạo và phát triển tại nơi làm việc. Nói một cách khác người lao động trong thời gian sắp tới sẽ có đóng góp ý kiến lớn hơn đến chiến lược phát triển chính bản thân mình

Cuối cùng, đặc điểm nền kinh tế Việt Nam là thị trường định hướng xã hội chủ nghĩa với hàm ý là một nền kinh tế theo mô hình hỗn hợp trong đó nền kinh tế thị trường được vận hành với định hướng của chính phủ theo mục tiêu chủ nghĩa xã hội. Tuy nhiên với những điều kiện còn hạn chế về cung, cầu lao động và hệ thống hỗ trợ, Việt Nam chúng ta chưa thể thực hiện ngay chiến lược nhà nước kiến tạo trong đó vai trò lớn nhất quyết định chiến lược hay mô hình NHRD lại thuộc về thị trường

Với tất cả các lý do kể trên, nhóm tác giả cho rằng Việt Nam nên thực hiện chiến lược phát triển nguồn nhân lực trong điều kiện nền kinh tế chuyển đổi (thuộc nhóm 2) trong đó vai trò của chính phủ vẫn là chủ đạo trong việc xây dựng chiến lược, hoạch định và đề ra kế hoạch thực thi.

Thực tế, ở Việt Nam vấn đề phát triển nguồn nhân lực, đặc biệt là nguồn nhân lực chất lượng cao đã được đặt ra từ lâu. Tại Đại hội Đảng lần thứ 8 năm 1996, Đảng ta khẳng định nguồn nhân lực là động lực chính tạo nên lực lượng sản xuất - nhân tố quyết định tốc độ và sự phát triển bền vững của phương thức sản xuất mới ở nước ta trong điều kiện hội nhập quốc tế. Muốn phát triển đất nước bền vững không thể không chăm lo phát triển con người. Đảng ta xác định: con người vừa là mục tiêu, vừa là động lực của sự phát triển. Nguồn lực cơ bản, to lớn, quyết định này phải có hàm lượng trí tuệ, phẩm chất ngày một cao mới có thể đáp ứng được sự nghiệp công nghiệp hóa, hiện đại hóa. Qua nhiều thảo luận và nghiên cứu thì đến năm 2011, chúng ta mới chính thức ban hành Chiến lược phát triển nhân lực Việt Nam thời kỳ 2011 - 2020, bản chiến lược NHRD đầu tiên được viết theo hướng nền kinh tế chuyển đổi tuy nhiên vẫn còn nhiều bất cập trong quá trình thực hiện do thiên nhiều theo mô hình chiến lược tập trung hóa. 
Để tạo tiền đề tốt nhất cho chiến lược phát triển nguồn nhân lực trong điều kiện nền kinh tế chuyển đổi phù hợp với chiến lược NHRD chuyển đổi phân tích ở trên: i) Thay đổi chất lượng đào tạo của hệ thống giáo dục công phù hợp với nhu cầu của thị trường lao động bằng cách trao nhiều quyền tự chủ hơn cho các đơn vị giáo dục công lập đồng thời mở rộng hệ thống giáo dục đào tạo tư nhân để tạo bước đột phá trong cải cách chất lượng giáo dục ii) Xây dựng mới hoặc điều chỉnh lại cơ chế phối hợp thực hiện chiến lược NHRD trong đó nên có một cơ quan đầu mối trực tiếp trực thuộc chính phủ chẳng hạn như Hội đồng nhân lực quốc gia phụ trách iii) Xây dựng hệ thống phản hồi trong đó tạo nhiều kênh để lắng nghe góp ý của các doanh nghiệp từng lĩnh vực iv) Cuối cùng là cơ quan đầu mối về nguồn nhân lực quốc gia xây dựng chiến lược phát triển nguồn nhân lực quốc gia phù hợp với chính sách phát triển kinh tế nói chung từng thời kỳ.

\section{Lời cảm ơn}

Bài báo là sản phẩm nghiên cứu của đề tài "Cơ sở khoa học xây dựng chiến lược phát triển nguồn nhân lực Việt Nam đáp ứng yêu cầu phát triển kinh tế - xã hội trong bối cảnh Cách mạng công nghiệp lần thứ 4" mã số KHGD/1620.ĐT.046.

\section{Tài liệu tham khảo}

[1] Kenneth Andrews, The Concept of Corporate Strategy, Dow Jones-Irwin, New York, 1971.

[2] Nguyễn Sinh Cúc, Nguồn nhân lực và phát triển nguồn nhân lực, Tạp chí Lí luận chính trị, Số 2 (2014) 18.
[3] UN, Human resources development for the $21^{\text {st }}$ century: Report of the Secretary - General, New York, 2017.

[4] J. Gold, R. Holden, P. Iles, J. Stewart, J. Beardwell, Human resource development theory and practice ( $2^{\text {nd }}$ ed.), Palgrave Macmillan, Basingstoke, London, 2013.

[5] H.C. Oh, M. Choi, Comparative advantage of OECD member countries' competitive advantage in National Human Resource Development System 14 (2013) 189-208.

[6] M. Alagaraja, J. Wang, Reflections on the invited response: Dominant themes in current NHRD research, Human Resource Development Review 11(4) (2012) 437-442.

[7] G.N. McLean, National HRD: What is the world is it?, trong Lee, Monica; Human Resource Development As We Know It: Speeches That Have Shaped the Field, EBSCOhost (2012) 196 - 208.

[8] P.K. Nair và các cộng sự, National Human Resource Development: A multi - level perspective, Texas, 2007.

[9] J. Bae, C. Rowley, Changes and continuities in South Korean HRM. Asia Pacific Business Review, 9 (4) (2003)76-105.

[10] Tống Mạnh Hùng, Hàn Quốc phát hiện và đào tạo nhân tài ngay từ khi còn là học sinh, Tạp chí điện tử Tài năng Việt, http://tainangviet.vn/han-quocphat-hien-va-dao-tao-nhan-tai-ngay-tu-khi-con-lahoc-sinh-dar2557/, 2018 (truy cập ngày 1/7/2019).

[11] E. Cho, N. McLean, What we discovered about NHRD and what it means for HRD. Advances in Developing Human Resources 6(3) (2004) 382393.

[12] Nguyễn Đắc Hưng, Phát triển nhân tài chấn hưng đất nước, NXB Chính trị quốc gia, 2007.

[13] Chu Văn Cấp và cộng sự, Giáo dục - đào tạo với phát triển nguồn nhân lực của Hàn Quốc và những gợi mở cho Việt Nam, Tạp chí Phát triển \& Hội nhập số 17 (27) (2014) 86 - 88.

[14] Bộ Kế hoạch và Đầu tư, Sách trắng doanh nghiệp nhỏ và vừa Việt Nam, Hà Nội, 2017. 